\title{
Transversus abdominis plane block with liposomal bupivacaine for pain control after cesarean delivery: a retrospective chart review
}

This article was published in the following Dove Press journal: Journal of Pain Research

\section{B Wycke Baker ${ }^{1-4}$ \\ Lea G Villadiego ${ }^{1,2}$ \\ Y Natasha Lake ${ }^{1,2}$ \\ Yazan Amin ${ }^{3}$ \\ Audra E Timmins ${ }^{3}$ \\ Laurie S Swaim ${ }^{3}$ \\ David W Ashton ${ }^{3}$}

'Department of Obstetrical and Gynecological Anesthesiology, Texas Children's Hospital Pavilion for Women, Houston, TX, USA; ${ }^{2}$ US Anesthesia Partners, Houston, TX, USA; ${ }^{3}$ Department of Obstetrics and Gynecology, Baylor College of Medicine, Houston, TX, USA; ${ }^{4}$ Department of Anesthesiology, Baylor College of Medicine, Houston, TX, USA
Correspondence: B Wycke Baker Department of Obstetrical and Gynecological Anesthesiology, Texas Children's Hospital Pavilion for Women, 665I Main Street, Suite FI075, Houston, TX 77030, USA

Tel +l 8328267442

Fax + I 8328257950

Email bwbaker@texaschildrens.org
Background: Adverse effects of opioid analgesics and potential for chronic use are limitations in the cesarean setting. Regional anesthesia using transversus abdominis plane (TAP) block postcesarean delivery may improve analgesia and reduce opioid consumption. Effectiveness of TAP block using liposomal bupivacaine (LB) to reduce post-cesarean pain is unknown.

Methods: We performed a single-center retrospective chart review of patients aged $\geq 18$ years who underwent cesarean delivery with a multimodal pain management protocol with or without TAP block with LB $266 \mathrm{mg}$. Assessments included postsurgical opioid consumption; area under the curve (AUC) of numeric rating scale pain scores from 0 to 3 days; proportion of opioid-free patients; discharge- and post-anesthesia care unit (PACU)-ready time; times to ambulation, solid food, and bowel movement; hospital length of stay (LOS); and adverse events (AEs). Data were analyzed in the total population and in first- and repeat-cesarean subgroups using Wilcoxon, chi-squared, and Student's $t$-tests.

Results: Of 201 patients, 101 were treated with LB TAP block (LB-TAPB) and 100 without LB-TAPB. Treatment with LB-TAPB vs without LB-TAPB significantly reduced mean postsurgical opioid consumption (total, 47\%; first-cesarean, 54\%; repeat-cesarean, $42 \% ; P<0.001$ each) and mean AUC of pain scores (total, 46\%; first-cesarean, 57\%; repeat-cesarean, 40\%; $P<0.001$ each). Patients treated with LB-TAPB had significantly shorter mean discharge-ready times ( 2.9 vs 3.6 days; $P=0.006$ ), PACU-ready times ( 138 vs 163 minutes; $P=0.028$ ), and LOS ( 2.9 vs 3.9 days; $P<0.001$ ). LB-TAPB significantly decreased mean times to ambulation and solid food by $39 \%$ and $31 \%(P<0.01$ each), respectively, and numerically reduced mean time to bowel movement $(26 \% ; P=0.05)$. Fewer patients treated with LB-TAPB vs without LB-TAPB reported an $\mathrm{AE}$ ( $34 \%$ vs $50 \%$; $P=0.026)$.

Conclusion: These results suggest multimodal pain management incorporating TAP block with LB $266 \mathrm{mg}$ is an effective approach to reducing opioid requirements and improving analgesia post-cesarean delivery.

Keywords: transversus abdominis plane block, liposomal bupivacaine, cesarean section, postoperative pain management

\section{Introduction}

Cesarean delivery was the most common US operating room procedure in 2014, accounting for $9 \%$ of such procedures ${ }^{1}$ and $32 \%$ of births. ${ }^{2}$ Many women experience moderate to severe post-cesarean pain. ${ }^{3}$ Inadequately managed postsurgical pain can interfere with maternal-infant bonding and is associated with delayed recovery, postpartum depression, persistent pain, and reduced success with breastfeeding. ${ }^{4}$ 
The benefits of opioid analgesics with regard to postcesarean pain must be weighed against the potential for adverse effects in the mother and infant. ${ }^{5}$ Opioid-related adverse events (ORAEs) such as nausea, vomiting, respiratory depression, and hypotension are distressing, can vary in severity, and in rare circumstances are life-threatening. ${ }^{5}$ In breastfed infants, maternal opioid use has the potential to cause central nervous system depression if the doses are high or use is prolonged. ${ }^{6}$ The current opioid epidemic in the $\mathrm{US}^{7,8}$ warrants vigilance toward opioid prescribing and any potential for opioid misuse and abuse after cesarean delivery. A retrospective health claims study including 201,662 patients who underwent cesarean delivery determined that these women have a $28 \%$ increased risk for chronic opioid use compared with those not undergoing a surgery. ${ }^{9} \mathrm{~A}$ recent retrospective, single-center study of postpartum opioid prescribing suggested that many women leaving the hospital with an opioid prescription reported no pain at discharge or used no opioids in the last 24 hours of hospitalization. ${ }^{10}$ Although women often do not consume all the prescribed medication, leftover opioids are potentially hazardous because they pose a risk for diversion. ${ }^{11,12}$ Recognizing the possible risks of long-term opioid use, benefits of reduced postsurgical opioid consumption, and that opioids are not always required for postsurgical pain, professional practice society guidelines ${ }^{13}$ have recommended implementation of multimodal postsurgical pain management strategies to reduce opioid use.

Multimodal approaches to control post-cesarean pain can include systemic opioids, nonsteroidal anti-inflammatory drugs, or acetaminophen; infiltration of local anesthetic at the incision site; epidural or intrathecal opioids; and transversus abdominis plane (TAP) block. ${ }^{13}$ Two meta-analyses of randomized controlled trials (RCTs) showed reductions in post-cesarean pain scores and opioid usage using TAP block compared with placebo when spinal morphine was omitted, ${ }^{14,15}$ whereas a third meta-analysis showed less consistent findings. ${ }^{16}$ In these same studies, in the presence of spinal opioids, the intervention showed no efficacy or inconsistent efficacy. ${ }^{14-16}$

Liposomal bupivacaine (LB, EXPAREL ${ }^{\circledR}$; Pacira Pharmaceuticals, Inc., Parsippany, NJ, USA) is a prolonged-release formulation of bupivacaine that is approved by the US Food and Drug Administration (FDA) for single-dose infiltration for postsurgical analgesia, ${ }^{17}$ including TAP block. LB has been shown to reduce postsurgical pain and opioid consumption for up to 72 hours when administered via local wound infiltration. ${ }^{18}$ In cesarean delivery, intraincisional infiltration of LB after completion of surgery has been shown to reduce opioid consumption compared with usual care. ${ }^{19}$ Although
TAP block with LB has shown efficacy in other settings such as donor nephrectomy ${ }^{20}$ and abdominal wall reconstruction, ${ }^{21}$ data are lacking regarding use for post-cesarean analgesia.

In light of this knowledge gap, we designed this retrospective chart review to evaluate the effectiveness and safety of a multimodal pain management protocol with or without LB TAP block (LB-TAPB) for cesarean delivery.

\section{Methods \\ Study design and patients}

This was a single-center retrospective review of charts from 201 consecutive women 18-65 years of age who underwent elective, unscheduled waiting list, or emergency cesarean delivery with anesthesia and post-cesarean pain management by one anesthesiologist (BWB) at Texas Children's Hospital Pavilion for Women between 2012 and 2015. The study was conducted in accordance with the International Conference on Harmonisation Good Clinical Practice and the Declaration of Helsinki and approved by an Institutional Review Board (IRB). Because data collection included deidentified patient records, the IRB granted a waiver of written informed consent.

\section{Postsurgical pain management protocol}

From 2012 to late 2014, the institution utilized a multimodal post-cesarean pain management protocol that comprised combined spinal-epidural anesthesia with intrathecal morphine $(100 \mu \mathrm{g})$ and supplemental intravenous (IV) analgesics. Dosing of IV analgesics was based on patient-reported pain intensity assessed using a numeric rating scale (NRS; range, 0 [no pain] to 10 [worst possible pain]). For patient-reported NRS scores of 1 to 5 , patients received three doses of IV acetaminophen $10 \mathrm{mg} / \mathrm{mL}$ ( $15 \mathrm{mg} / \mathrm{kg}$ if body weight $<50 \mathrm{~kg}$; $1,000 \mathrm{mg}$ if body weight $\geq 50 \mathrm{~kg}$ ) every 6 hours, alternated with three doses of IV ketorolac $30 \mathrm{mg}$ every 6 hours for 24 hours. For patient-reported NRS scores of 6 to 10, patients received IV nalbuphine $2 \mathrm{mg}$, a mixed opioid agonist-antagonist combination, every 2 hours as needed for breakthrough pain for 24 hours. In late 2014, ultrasound-guided LB-TAPB was added to the protocol. Patients received bilateral singleshot injections of $10 \mathrm{~mL} \mathrm{LB}(133 \mathrm{mg})$ admixed with $15 \mathrm{~mL}$ $0.25 \%$ bupivacaine $\mathrm{HCl}$ expanded with $15 \mathrm{~mL}$ normal saline (total $40 \mathrm{~mL}$ injection per side).

\section{Assessments}

Data were collected and entered into a secure Health Insurance Portability and Accountability Act of 1996 (HIPAA)compliant, cloud-based OpenClinica (Waltham, MA) data 
clarification form by designated providers at the institution. All records were deidentified, and no identifiable protected health information was extracted or accessed during the study, pursuant to HIPAA guidelines. ${ }^{22}$ Efficacy end points included postsurgical opioid consumption (morphine equivalent dose [MED]) overall and on postsurgical days 2 and 3 ; proportion of opioid-free patients; area under the curve (AUC) of NRS pain intensity scores through postsurgical day 3 (in patients with a length of stay [LOS] of 3 days) and on postsurgical days 2 and 3; time to discharge readiness from the post-anesthesia care unit (PACU); times to ambulation, solid food, and bowel movement; time to discharge readiness; discharge location; and hospital LOS. Adverse events (AEs) were assessed through day 3 .

\section{Statistical analyses}

Data were analyzed for the overall study population, and exploratory analyses were conducted in subgroups of patients undergoing first- vs repeat-cesarean ( $\geq 1$ previous cesarean) delivery. Demographic variables were summarized using descriptive statistics. Continuous variables were summarized as mean (SD) and compared between groups using a twotailed Student's $t$-test or Wilcoxon signed-rank test. Categorical variables were summarized as $\mathrm{n}(\%)$ and analyzed using a Pearson's chi-squared test. All analyses used an alpha of 0.05 .

\section{Results}

The analysis included 101 patients who received multimodal pain management with LB-TAPB and 100 who received multimodal pain management without LB-TAPB. For 90 patients this was their first cesarean delivery, whereas 111 patients had previously delivered via cesarean. There were no clinically important or statistically significant differences in demographics or baseline characteristics between groups (Table 1).

\section{Effectiveness}

Multimodal pain management with LB-TAPB significantly reduced mean postsurgical opioid consumption by $47 \%$ in the total population and by $54 \%$ and $42 \%$ in the first- and repeat-cesarean subgroups, respectively (Table 2). When analyzed by postsurgical day, reductions in opioid consumption with vs without LB-TAPB were significant for day 3 (total population, $47 \%$; first, $60 \%$; repeat, $38 \%$ ), with nonsignificant numeric reductions on postsurgical day 2 (total population, $43 \%$; first, $63 \%$; repeat, $33 \%$ ). In the total population, a significantly greater percentage of patients treated with LB-TAPB (12\%) vs without LB-TAPB (3\%) consumed no opioids after surgery $(P=0.017)$. There was no significant difference in the proportion of opioid-free patients in the first-cesarean subgroup ( $6 \%$ vs $5 \%, P=0.916$ ). In the repeatcesarean subgroup, $15 \%$ of patients treated with LB-TAPB vs no patients treated without LB-TAPB were opioid-free.

Multimodal pain management with LB-TAPB significantly reduced mean AUC of pain scores by $46 \%$ in the total population and by $57 \%$ and $40 \%$ in the first- and repeatcesarean subgroups, respectively (Table 2 ). When analyzed by postsurgical day, improvements in pain scores in the total population were significant for day 3 (44\%), with a nonsignificant numeric reduction on day 2 (41\%). Reductions in pain scores were also significant for day 3 in the first- $(52 \%)$ and repeat-cesarean subgroups (40\%).

In the total population, patients treated with LB-TAPB vs without LB-TAPB had significantly reduced mean (95\% CI) discharge-ready time (Figure 1A) and PACU-ready time (138 [122.8-153.2] vs 163 [103.2-222.8] minutes, respectively; $P=0.028)$. Discharge-ready time was significantly decreased with LB-TAPB vs without LB-TAPB in the first-cesarean subgroup and numerically decreased in the repeat-cesarean subgroup (Figure 1B).

Table I Patient demographics and baseline clinical characteristics

\begin{tabular}{|c|c|c|c|c|c|c|c|c|c|}
\hline \multirow[t]{2}{*}{ Characteristics } & \multicolumn{3}{|l|}{ Total } & \multicolumn{3}{|c|}{ First-cesarean } & \multicolumn{3}{|c|}{ Repeat-cesarean } \\
\hline & $\begin{array}{l}\text { With } \\
\text { LB-TAPB } \\
(n=101)\end{array}$ & $\begin{array}{l}\text { Without } \\
\text { LB-TAPB } \\
(n=100)\end{array}$ & $P$-value ${ }^{a}$ & $\begin{array}{l}\text { With } \\
\text { LB-TAPB } \\
(n=34)\end{array}$ & $\begin{array}{l}\text { Without } \\
\text { LB-TAPB } \\
(n=56)\end{array}$ & $P$-value ${ }^{a}$ & $\begin{array}{l}\text { With } \\
\text { LB-TAPB } \\
(n=67)\end{array}$ & $\begin{array}{l}\text { Without } \\
\text { LB-TAPB } \\
(n=44)\end{array}$ & $P$-value ${ }^{a}$ \\
\hline Mean (SD) age, years & $33(6)$ & $35(6)$ & 0.089 & $33(6)$ & $34(6)$ & 0.244 & $34(6)$ & $36(6)$ & 0.094 \\
\hline Mean (SD) BMI, $\mathrm{kg} / \mathrm{m}^{2}$ & $32.4(6.8)$ & $32.7(6.5)$ & 0.705 & $30.4(5.5)$ & $33.0(7.5)$ & 0.091 & $33.4(7.2)$ & $32.4(4.9)$ & 0.402 \\
\hline ASA status, $\mathrm{n}(\%)$ & $\mathrm{n}=100$ & $n=99$ & 0.224 & $n=33$ & $n=55$ & 0.454 & $n=67$ & $\mathrm{n}=44$ & 0.166 \\
\hline 2 & $77(77.0)$ & $83(83.8)$ & & $30(90.9)$ & $47(85.5)$ & & $47(70.2)$ & $36(81.8)$ & \\
\hline 3 & $23(23.0)$ & $16(16.2)$ & & $3(9.1)$ & $8(14.6)$ & & $20(29.9)$ & $8(18.2)$ & \\
\hline
\end{tabular}

Notes: aP-values were calculated using a two-tailed Student's $t$-test or Wilcoxon signed-rank test (continuous variables) or a Pearson's chi-squared test (categorical variables). Abbreviations: ASA, American Society of Anesthesiologists; BMI, body mass index; LB-TAPB, transversus abdominis plane block with liposomal bupivacaine. 
Table 2 Mean total postsurgical opioid consumption and AUC of NRS pain scores

\begin{tabular}{|c|c|c|c|c|c|c|c|c|c|}
\hline \multirow{2}{*}{$\begin{array}{l}\text { Arithmetic } \\
\text { mean (SD) }\end{array}$} & \multicolumn{3}{|l|}{ Total } & \multicolumn{3}{|c|}{ First-cesarean } & \multicolumn{3}{|c|}{ Repeat-cesarean } \\
\hline & $\begin{array}{l}\text { With } \\
\text { LB-TAPB } \\
(n=10 I)\end{array}$ & $\begin{array}{l}\text { Without } \\
\text { LB-TAPB } \\
(n=100)\end{array}$ & $P$-value ${ }^{a}$ & $\begin{array}{l}\text { With } \\
\text { LB-TAPB } \\
(n=34)\end{array}$ & $\begin{array}{l}\text { Without } \\
\text { LB-TAPB } \\
(n=56)\end{array}$ & $P$-value ${ }^{a}$ & $\begin{array}{l}\text { With } \\
\text { LB-TAPB } \\
(n=67)\end{array}$ & $\begin{array}{l}\text { Without } \\
\text { LB-TAPB } \\
(n=44)\end{array}$ & $P$-value ${ }^{a}$ \\
\hline $\begin{array}{l}\text { Total postsurgical } \\
\text { opioid consumption } \\
\text { (MED), mg }\end{array}$ & $\begin{array}{l}n=89 \\
41.9(37.4)\end{array}$ & $\begin{array}{l}n=97 \\
79.6(60.2)\end{array}$ & $<0.001$ & $\begin{array}{l}\mathrm{n}=32 \\
38.1(34.2)\end{array}$ & $\begin{array}{l}n=53 \\
82.1(61.9)\end{array}$ & $<0.001$ & $\begin{array}{l}n=57 \\
44.0(39.1)\end{array}$ & $\begin{array}{l}n=44 \\
76.5(58.7)\end{array}$ & $<0.001$ \\
\hline Postsurgical day I & $\begin{array}{l}n=1 \\
25\end{array}$ & $\begin{array}{l}n=1 \\
60\end{array}$ & ND & NA & NA & NA & $\begin{array}{l}n=1 \\
25\end{array}$ & $\begin{array}{l}n=1 \\
60\end{array}$ & ND \\
\hline Postsurgical day 2 & $\begin{array}{l}n=17 \\
29.2(25.4)\end{array}$ & $\begin{array}{l}\mathrm{n}=8 \\
51.3(51.8)\end{array}$ & 0.482 & $\begin{array}{l}n=3 \\
26.7(15.3)\end{array}$ & $\begin{array}{l}n=2 \\
72.5(95.5)\end{array}$ & 1.000 & $\begin{array}{l}n=14 \\
29.7(27.5)\end{array}$ & $\begin{array}{l}n=6 \\
44.2(4 \mid .2)\end{array}$ & 0.508 \\
\hline Postsurgical day 3 & $\begin{array}{l}n=49 \\
44.9(42.0)\end{array}$ & $\begin{array}{l}n=42 \\
84.4(64.1)\end{array}$ & $<0.001$ & $\begin{array}{l}n=20 \\
33.1(34.8)\end{array}$ & $\begin{array}{l}n=17 \\
83.7(75.4)\end{array}$ & 0.002 & $\begin{array}{l}n=29 \\
52.9(45.1)\end{array}$ & $\begin{array}{l}n=25 \\
84.8(56.8)\end{array}$ & 0.007 \\
\hline Total AUC of NRS & $\mathrm{n}=54$ & $n=49$ & & $n=19$ & $\mathrm{n}=17$ & & $\mathrm{n}=35$ & $\mathrm{n}=32$ & \\
\hline $\begin{array}{l}\text { pain scores from } 0 \\
\text { to } 3 \text { days }^{\mathrm{b}}\end{array}$ & I $32.8(98.3)$ & $246.3(102.8)$ & $<0.001$ & $109.0(82.7)$ & $250.7(109.4)$ & $<0.001$ & I 45.7 (I04.7) & $244.0(100.8)$ & $<0.001$ \\
\hline Postsurgical day I & $\begin{array}{l}\mathrm{n}=1 \\
71.7\end{array}$ & $\begin{array}{l}n=1 \\
257.3\end{array}$ & ND & NA & NA & NA & $\begin{array}{l}n=1 \\
71.7\end{array}$ & $\begin{array}{l}n=1 \\
257.3\end{array}$ & ND \\
\hline Postsurgical day 2 & $\begin{array}{l}n=12 \\
97.2(77.3)\end{array}$ & $\begin{array}{l}n=7 \\
163.4(109.1)\end{array}$ & 0.305 & $\begin{array}{l}n=3 \\
53.8(37.3)\end{array}$ & $\begin{array}{l}n=1 \\
252.9(112.9)\end{array}$ & 0.437 & $\begin{array}{l}\mathrm{n}=9 \\
111.7(83.3)\end{array}$ & $\begin{array}{l}n=6 \\
\mid 48.5(|| \mid .4)\end{array}$ & 0.773 \\
\hline Postsurgical day 3 & $\begin{array}{l}n=4 \mid \\
\mid 44.7(102.7)\end{array}$ & $\begin{array}{l}n=41 \\
260.2(97.4)\end{array}$ & $<0.001$ & $\begin{array}{l}n=16 \\
119.4(85.4)\end{array}$ & $\begin{array}{l}n=16 \\
250.6(112.9)\end{array}$ & 0.005 & $\begin{array}{l}n=25 \\
160.9(111.0)\end{array}$ & $\begin{array}{l}n=25 \\
266.4(87.9)\end{array}$ & 0.001 \\
\hline
\end{tabular}

Notes: ${ }^{a}$-values were calculated using a two-tailed Student's $t$-test or Wilcoxon signed-rank test. ${ }^{b}$ Analysis included only those patients with a length of stay of 3 days. Abbreviations: AUC, area under the curve; LB-TAPB, transversus abdominis plane block with liposomal bupivacaine; MED, morphine equivalent dose; NA, not available; ND, not determined; NRS, numeric rating scale.
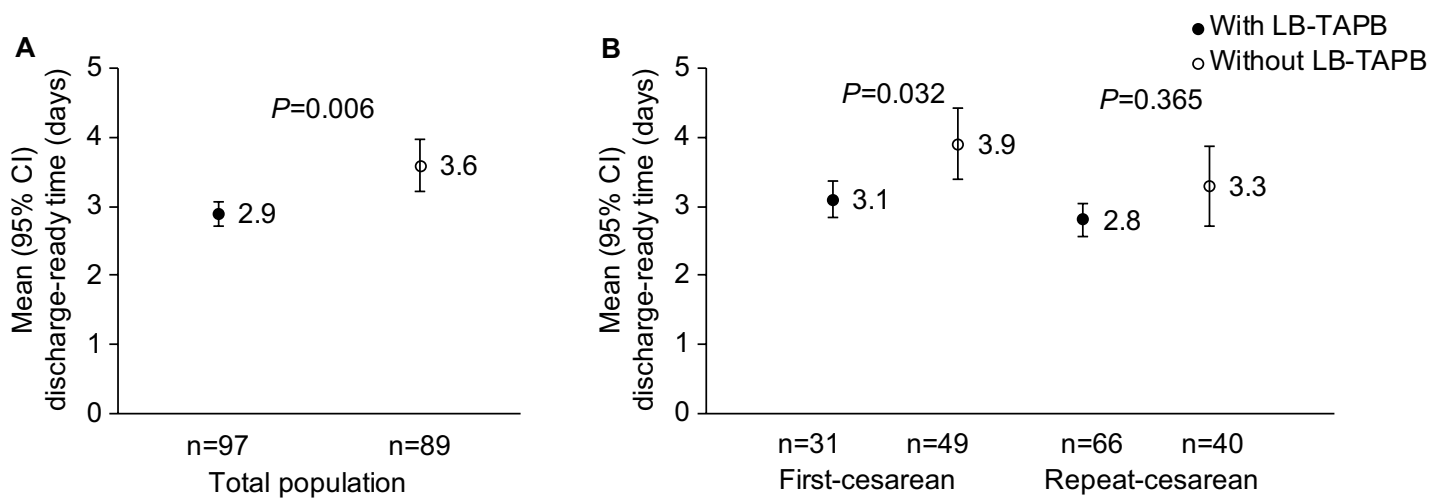

Figure I Mean discharge-ready time in the (A) total patient population and (B) first- and repeat-cesarean patients. $P$-value was calculated using Student's $t$-test. Abbreviation: LB-TAPB, transversus abdominis plane block with liposomal bupivacaine.

In the total population, patients treated with LB-TAPB vs without LB-TAPB had significantly reduced mean hospital LOS (Figure 2A). In the first-cesarean subgroup, there was also a significant reduction in LOS in the group receiving LBTAPB (Figure 2B), whereas in the repeat-cesarean subgroup, there was a nonsignificant numeric reduction (Figure 2B). All patients were discharged to home.

Multimodal pain management with LB-TAPB significantly decreased mean time to ambulation and solid food in the total population, and there was a nonsignificant numeric reduction in mean time to bowel movement (Table 3). In the first-cesarean group, LB-TAPB significantly decreased all functional outcomes, whereas nonsignificant numeric reductions were seen in the repeat-cesarean subgroup (Table 3).

\section{Safety}

In the total population, significantly fewer patients receiving multimodal pain management with LB-TAPB vs without LB-TAPB reported an AE (Table 4). The most commonly reported ORAEs were nausea, pruritus, and vomiting (Table 4). In the first-cesarean group, numerically fewer patients reported an AE with LB-TAPB vs without LB-TAPB, 

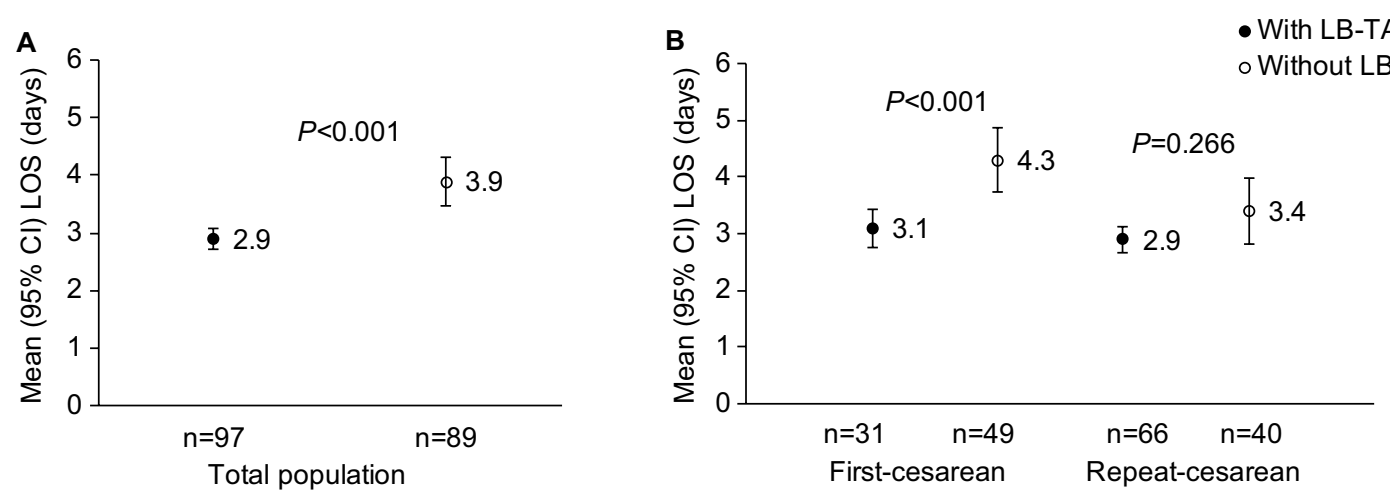

Figure 2 Mean hospital LOS in the (A) total patient population and (B) first- and repeat-cesarean patients. P-value was calculated using Student's $t$-test. Abbreviations: LB-TAPB, transversus abdominis plane block with liposomal bupivacaine; LOS, length of stay.

Table 3 Mean times to ambulation, solid food, and bowel movement

\begin{tabular}{|c|c|c|c|c|c|c|c|c|c|}
\hline \multirow{2}{*}{$\begin{array}{l}\text { Mean (SD), } \\
\text { hours }\end{array}$} & \multicolumn{3}{|l|}{ Total } & \multicolumn{3}{|c|}{ First-cesarean } & \multicolumn{3}{|c|}{ Repeat-cesarean } \\
\hline & $\begin{array}{l}\text { With } \\
\text { LB-TAPB } \\
(n=67)\end{array}$ & $\begin{array}{l}\text { Without } \\
\text { LB-TAPB } \\
(n=60)\end{array}$ & $P$-value ${ }^{a}$ & $\begin{array}{l}\text { With } \\
\text { LB-TAPB } \\
(n=19)\end{array}$ & $\begin{array}{l}\text { Without } \\
\text { LB-TAPB } \\
(n=29)\end{array}$ & $P$-value ${ }^{a}$ & $\begin{array}{l}\text { With } \\
\text { LB-TAPB } \\
(n=48)\end{array}$ & $\begin{array}{l}\text { Without } \\
\text { LB-TAPB } \\
(n=31)\end{array}$ & $P$-value ${ }^{a}$ \\
\hline Time to ambulation & I8.7 (8.4) & $30.7(27.0)$ & $<0.001$ & I7.7 (7.4) & $34.4(29.7)$ & 0.007 & I9.1 (8.9) & $27.2(24.2)$ & 0.082 \\
\hline Time to solid food & $22.3(13.1)$ & $32.1(25.4)$ & 0.008 & I7.7 (8.5) & $37.1(27.9)$ & 0.001 & $24.1(14.2)$ & $27.5(22.2)$ & 0.452 \\
\hline $\begin{array}{l}\text { Time to bowel } \\
\text { movement }\end{array}$ & $21.6(14.5)$ & $29.1(26.5)$ & 0.05 & I6.5 (II.8) & $34.4(29.5)$ & 0.005 & $23.5(15.0)$ & $24.1(22.9)$ & 0.909 \\
\hline
\end{tabular}

Note: aP-value was calculated using Student's t-test.

Abbreviation: LB-TAPB, transversus abdominis plane block with liposomal bupivacaine.

Table 4 Adverse events

\begin{tabular}{|c|c|c|c|c|c|c|c|c|c|}
\hline \multirow[t]{2}{*}{ n (\%) } & \multicolumn{3}{|l|}{ Total } & \multicolumn{3}{|c|}{ First-cesarean } & \multicolumn{3}{|c|}{ Repeat-cesarean } \\
\hline & $\begin{array}{l}\text { With } \\
\text { LB-TAPB } \\
(n=10 I)\end{array}$ & $\begin{array}{l}\text { Without } \\
\text { LB-TAPB } \\
(n=100)\end{array}$ & $P$-value ${ }^{a}$ & $\begin{array}{l}\text { With } \\
\text { LB-TAPB } \\
(n=34)\end{array}$ & $\begin{array}{l}\text { Without } \\
\text { LB-TAPB } \\
(n=56)\end{array}$ & $P$-value ${ }^{a}$ & $\begin{array}{l}\text { With } \\
\text { LB-TAPB } \\
(n=67)\end{array}$ & $\begin{array}{l}\text { Without } \\
\text { LB-TAPB } \\
(n=44)\end{array}$ & $P$-value ${ }^{a}$ \\
\hline Patients with $\geq \mathrm{I} A E$ & $\begin{array}{l}n=101 \\
34(33.7)\end{array}$ & $\begin{array}{l}n=93 \\
46(49.5)\end{array}$ & 0.026 & $\begin{array}{l}\mathrm{n}=34 \\
\mathrm{I}\end{array}$ & $\begin{array}{l}n=5 I \\
23(45.1)\end{array}$ & 0.240 & $\begin{array}{l}n=67 \\
23(34.3)\end{array}$ & $\begin{array}{l}n=42 \\
23(54.8)\end{array}$ & 0.036 \\
\hline $\begin{array}{l}\text { ORAEs of interest } \\
\text { Nausea }\end{array}$ & $\begin{array}{l}n=43 \\
16(37.2)\end{array}$ & $\begin{array}{l}n=76 \\
38(50.0)\end{array}$ & 0.305 & $\begin{array}{l}n=13 \\
6(46.2)\end{array}$ & $\begin{array}{l}n=35 \\
17(48.6)\end{array}$ & 0.988 & $\begin{array}{l}\mathrm{n}=30 \\
10(33.3)\end{array}$ & $\begin{array}{l}\mathrm{n}=4 \mathrm{I} \\
21(5 \mid .2)\end{array}$ & 0.252 \\
\hline Pruritus & $19(44.2)$ & $30(39.5)$ & & $5(38.5)$ & $13(37.1)$ & & $14(46.7)$ & $17(4 \mid .5)$ & \\
\hline Vomiting & $7(16.3)$ & $8(10.5)$ & & $2(15.4)$ & $5(14.3)$ & & $5(16.7)$ & $3(7.3)$ & \\
\hline Abdominal pain & I (2.3) & 0 & & 0 & 0 & & I (3.3) & 0 & \\
\hline
\end{tabular}

Note: ${ }^{\text {a }}$-value was calculated using chi-squared test.

Abbreviations: AE, adverse event; LB-TAPB, transversus abdominis plane block with liposomal bupivacaine; ORAEs, opioid-related adverse events.

and in the repeat-cesarean group significantly fewer patients reported an AE with LB-TAPB vs without LB-TAPB.

\section{Discussion}

In this retrospective study, administering TAP block with LB $266 \mathrm{mg}$ as part of a multimodal post-cesarean pain management protocol significantly reduced pain intensity and total inpatient postsurgical opioid consumption. In addition, this pain management approach significantly improved discharge- and PACU-ready times, functional recovery, and LOS. Further, patients receiving multimodal pain management with LB-TAPB reported significantly fewer AEs overall. These results suggest that multimodal pain management incorporating LB-TAPB is an effective approach to improving outcomes in women undergoing cesarean delivery.

Our results add to the growing literature on regional analgesia approaches such as TAP block and quadratus lumborum block for cesarean section. Results of a meta-analysis 
of RCTs evaluating the effectiveness of TAP block with bupivacaine, ropivacaine, or levobupivacaine after cesarean delivery show superiority over placebo or no block with respect to analgesia and opioid consumption, although showing little benefit when added to or compared with intrathecal morphine alone. ${ }^{23}$ A systematic review of eleven RCTs demonstrated high levels of patient satisfaction, increased time to first analgesia request, and reduced postoperative nausea and vomiting with the addition of TAP block vs placebo to spinal anesthesia for cesarean delivery. ${ }^{24}$

Reduced opioid consumption was observed in an earlier retrospective case-control study using LB infiltrated at the cesarean incision site, ${ }^{19}$ an approach that has shown comparable effectiveness to TAP block in this surgical setting. ${ }^{25}$ Although a recent pilot RCT evaluating wound infiltration with LB for post-cesarean pain showed no treatment effect with respect to pain on movement at 48 hours, the primary outcome, results may have been affected by an apparent floor effect, as pain scores in the placebo group were lower than those used to power the study. ${ }^{26}$ In our study, multimodal pain management incorporating LB-TAPB produced prolonged analgesia, as demonstrated by a $46 \%$ improvement in AUC pain scores and a $44 \%$ improvement in pain scores on postsurgical day 3 . Consistent with these analgesic benefits, multimodal pain management incorporating LB-TAPB significantly reduced opioid consumption by $47 \%$ overall and on day 3. Although there were similar trends for pain scores and opioid use on postsurgical day 2 , the between-group differences did not reach significance, likely due to the small sample size for this time point.

These findings are important in light of the opioid epidemic in the $\mathrm{US}^{27}$ and the shift toward multimodal pain management approaches that can provide effective opioidsparing post-cesarean analgesia. Prescription of postsurgical opioids is nearly universal among surgical patients, ${ }^{28,29}$ including women undergoing cesarean delivery. ${ }^{10} \mathrm{Up}$ to $14 \%$ of patients prescribed an opioid for postsurgical pain experience an ORAE, which is associated with increased hospital LOS, greater risk of readmission, greater inpatient mortality, and higher total costs. ${ }^{28,29}$ Cesarean delivery is associated with a $28 \%$ increase in the incidence of persistent postsurgical opioid use, ${ }^{9}$ and leftover opioid medication has the potential for diversion. ${ }^{12,30}$ The Centers for Disease Control and American College of Surgeons have both recommended that physicians limit the use of opioids postoperatively. ${ }^{31,32}$ Our findings suggest that the addition of LB-TAPB to a multimodal pain management protocol may be an effective opioid-sparing strategy for cesarean delivery.
The advantages of TAP block for cesarean delivery should be weighed against risks, including the rare but potentially serious occurrence of local anesthetic systemic toxicity (LAST) subsequent to inadvertent intravenous administration. ${ }^{33}$ TAP block requires the injection of relatively high volumes and drug doses into a vascular space, which, along with pregnancy, ${ }^{33}$ may increase LAST risk. ${ }^{33,34}$ Preventive measures include the use of ultrasound guidance, ${ }^{33}$ consistent with technique in the current study. LB was not injected unless the TAP plane was clearly visualized, aspiration for the return of blood was performed before and after each $5 \mathrm{~mL}$ injection, and patients were monitored closely for signs and symptoms of LAST. Circulating plasma concentrations of local anesthetics are especially pertinent to the occurrence of LAST. ${ }^{33}$ Compared to immediate-release bupivacaine $\mathrm{HCl}$, LB displays a slower release of bupivacaine and a lower initial maximum plasma concentration followed by extended release over time. ${ }^{35} \mathrm{~A}$ recent analysis of the FDA AE reporting database suggests that the incidence of possible LAST cases with LB is similar to or less than that with other injectable local anesthetics. ${ }^{36}$

Cesarean delivery is associated with $\sim 50 \%$ greater costs compared with vaginal delivery for both Medicaid and commercial health insurance payers. ${ }^{37}$ LOS and ORAEs are important drivers of costs of care in surgical patients. ${ }^{28,38}$ Although the current study did not directly assess costs associated with LB-TAPB, the observed improvements in functional recovery, discharge-ready time, and LOS suggest a potential for overall cost savings. However, this requires substantiation in future prospective studies evaluating hospital-related costs associated with LB-TAPB vs TAP block with other local anesthetics.

Limitations of this study include its retrospective nature, which required accurate record keeping to maintain data validity. Baseline demographic and clinical characteristics were limited, and results may have been affected by uncontrolled confounding factors such as imbalance in the number of first- and repeat-cesarean patients in the two treatment groups. The use of a single site and anesthesiologist may limit the generalizability of the findings, in addition to being a potential source of bias; however, this may also be considered a strength because it ensured consistency with regard to protocols and infiltration techniques. The subgroup analyses in patients undergoing a first- vs repeat-cesarean delivery were exploratory, likely underpowered due to small sample size, and potentially affected by uncontrolled confounding factors. Prospective RCTs evaluating the effectiveness of LBTAPB vs TAP block with other local anesthetics are needed 
to further define the utility of this approach for cesarean delivery. Evaluation of effects on lactation, breastfeeding, and bupivacaine levels in breast milk would further inform the effects of this approach on functional recovery.

\section{Conclusion}

These results suggest that multimodal pain management incorporating TAP block with LB $266 \mathrm{mg}$ is an effective approach to reducing opioid reliance and improving analgesia after cesarean delivery with no unexpected safety signals. These results are important in light of the need for opioid-sparing pain management strategies and provide the basis for a future prospective RCT to assess the efficacy of a standardized multimodal postsurgical pain management protocol incorporating LB-TAPB for post-cesarean analgesia.

\section{Ethics approval and informed consent}

This study (H-40158) was approved by the Institutional Review Board for Human Subject Research for Baylor College of Medicine and Affiliated Hospitals. Because data collection included deidentified patient records, the IRB granted a waiver of written informed consent.

\section{Data availability}

Data requests will be considered on an individual basis. Requests should go to the corresponding author.

\section{Acknowledgments}

The authors would like to acknowledge Amiee Kang, MPH, a former employee of Pacira Pharmaceuticals, Inc., for assistance with statistical analyses. Editorial support for development of this manuscript was provided by Krystina Neuman, PhD, at C4 MedSolutions, LLC (Yardley, PA), a CHC Group company, and was funded by Pacira Pharmaceuticals, Inc. Pacira Pharmaceuticals, Inc. was involved in the analysis and interpretation of the data and review of the manuscript. This paper was presented at the SOAP 50th Annual Meeting held in Miami, FL, USA, May 9-13, 2018, as a poster and published online at https://epostersonline. com/soap2018/node/194.

\section{Author contributions}

All authors participated in the study conception or design or acquisition, analysis, or interpretation of the work and contributed to drafting or revising the article; gave final approval of the version to be published; and agree to be accountable for all aspects of the work.

\section{Disclosure}

BW Baker received research funding and consulting fees from Pacira Pharmaceuticals, Inc. LG Villadiego received research funding from Pacira Pharmaceuticals, Inc. The authors report no other conflicts of interest in this work.

\section{References}

1. McDermott K, Freeman W, Elixhauser A. Overview of operating room procedures during inpatient stays in U.S. hospitals, 2014. HCUP Statistical Brief. 2017;233:1-18.

2. Martin JA, Hamilton BE, Osterman MJ, Driscoll AK, Mathews TJ. Births: final data for 2015. Natl Vital Stat Rep. 2017;66(1):1-70.

3. Pan PH, Tonidandel AM, Aschenbrenner CA, Houle TT, Harris LC, Eisenach JC. Predicting acute pain after cesarean delivery using three simple questions. Anesthesiology. 2013;118(5):1170-1179.

4. Sutton CD, Carvalho B. Optimal pain management after cesarean delivery. Anesthesiol Clin. 2017;35(1):107-124.

5. Armstrong S, Fernando R. Side effects and efficacy of neuraxial opioids in pregnant patients at delivery: a comprehensive review. Drug Saf. 2016;39(5):381-399.

6. Chow CK, Koren G. Sedating drugs and breastfeeding. Can Fam Physician. 2015;61(3):241-243.

7. Ostling PS, Davidson KS, Anyama BO, Helander EM, Wyche MQ, Kaye AD. America's opioid epidemic: a comprehensive review and look into the rising crisis. Curr Pain Headache Rep. 2018;22(5):32.

8. American College of Surgeons [homepage on the Internet]. Statement on the opioid abuse epidemic. Available from: http://bulletin.facs.org/2017/08/ statement-on-the-opioid-abuse-epidemic/\#.W0UMXNJKjcs. Accessed July 10, 2018.

9. Sun EC, Darnall BD, Baker LC, Mackey S. Incidence of and risk factors for chronic opioid use among opioid-naive patients in the postoperative period. JAMA Intern Med. 2016;176(9):1286-1293.

10. Badreldin N, Grobman WA, Chang KT, Yee LM. Opioid prescribing patterns among postpartum women. Am J Obstet Gynecol. 2018;219(1):103.e1-103.e8.

11. Bateman BT, Cole NM, Maeda A, et al. Patterns of opioid prescription and use after cesarean delivery. Obstet Gynecol. 2017;130(1):29-35.

12. Osmundson SS, Schornack LA, Grasch JL, Zuckerwise LC, Young JL, Richardson MG. Postdischarge opioid use after cesarean delivery. Obstet Gynecol. 2017;130(1):36-41.

13. Chou R, Gordon DB, de Leon-Casasola OA, et al. Management of postoperative pain: a clinical practice guideline from the American Pain Society, the American Society of Regional Anesthesia and Pain Medicine, and the American Society of Anesthesiologists' Committee on Regional Anesthesia, Executive Committee, and Administrative Council. J Pain. 2016;17(2):131-157.

14. Abdallah FW, Halpern SH, Margarido CB. Transversus abdominis plane block for postoperative analgesia after Caesarean delivery performed under spinal anaesthesia? A systematic review and meta-analysis. $\mathrm{Br} J$ Anaesth. 2012;109(5):679-687.

15. Baeriswyl M, Kirkham KR, Kern C, Albrecht E. The analgesic efficacy of ultrasound-guided transversus abdominis plane block in adult patients: a meta-analysis. Anesth Analg. 2015;121(6):1640-1654.

16. Mishriky BM, George RB, Habib AS. Transversus abdominis plane block for analgesia after Cesarean delivery: a systematic review and meta-analysis. Can J Anaesth. 2012;59(8):766-778.

17. EXPAREL ${ }^{\circledR}$ (bupivacaine liposome injectable suspension) [prescribing information]. San Diego, CA: Pacira Pharmaceuticals, Inc.; 2018.

18. Bergese SD, Ramamoorthy S, Patou G, Bra]mlett K, Gorfine SR, Candiotti KA. Efficacy profile of liposome bupivacaine, a novel formulation of bupivacaine for postsurgical analgesia. J Pain Res. 2012;5:107-116.

19. Parikh P, Sunesara I, Singh Multani S, Patterson B, Lutz E, Martin JN Jr. Intra-incisional liposomal bupivacaine and its impact on postcesarean analgesia: a retrospective study. J Matern Fetal Neonatal Med. Epub 2017 Nov 7. 
20. Hutchins JL, Kesha R, Blanco F, Dunn T, Hochhalter R. Ultrasoundguided subcostal transversus abdominis plane blocks with liposomal bupivacaine vs. non-liposomal bupivacaine for postoperative pain control after laparoscopic hand-assisted donor nephrectomy: a prospective randomised observer-blinded study. Anaesthesia. 2016;71(8):930-937.

21. Fayezizadeh M, Majumder A, Neupane R, Elliott HL, Novitsky YW. Efficacy of transversus abdominis plane block with liposomal bupivacaine during open abdominal wall reconstruction. Am J Surg. 2016;212(3):399-405.

22. 104th US Congress. Health Insurance Portability and Accountability Act of 1996. Public Law 104-191. Washington, DC: US Government Publishing Office; 1996.

23. Champaneria R, Shah L, Wilson MJ, Daniels JP. Clinical effectiveness of transversus abdominis plane (TAP) blocks for pain relief after caesarean section: a meta-analysis. Int J Obstet Anesth. 2016;28:45-60.

24. Fusco P, Scimia P, Paladini G, et al. Transversus abdominis plane block for analgesia after cesarean delivery. A systematic review. Minerva Anestesiol. 2015;81(2):195-204.

25. Tawfik MM, Mohamed YM, Elbadrawi RE, Abdelkhalek M, Mogahed MM, Ezz HM. Transversus abdominis plane block versus wound infiltration for analgesia after cesarean delivery: a randomized controlled trial. Anesth Analg. 2017;124(4):1291-1297.

26. Prabhu M, Clapp MA, McQuaid-Hanson E, et al. Liposomal bupivacaine block at the time of cesarean delivery to decrease postoperative pain: a randomized controlled trial. Obstet Gynecol. 2018;132(1): 70-78.

27. Centers for Disease Control and Prevention [homepage on the Internet]. Opioid overdose. Available from: https://www.cdc.gov/drugoverdose/ index.html. Accessed July 10, 2018.

28. Kessler ER, Shah M, Gruschkus SK, Raju A. Cost and quality implications of opioid-based postsurgical pain control using administrative claims data from a large health system: opioid-related adverse events and their impact on clinical and economic outcomes. Pharmacotherapy. 2013;33(4):383-391.
29. Minkowitz HS, Gruschkus SK, Shah M, Raju A. Adverse drug events among patients receiving postsurgical opioids in a large health system: risk factors and outcomes. Am J Health Syst Pharm. 2014;71(18):1556-1565.

30. Bartels K, Mayes LM, Dingmann C, Bullard KJ, Hopfer CJ, Binswanger IA. Opioid use and storage patterns by patients after hospital discharge following surgery. PLoS One. 2016;11(1):e0147972.

31. Centers for Disease Control and Prevention [homepage on the Internet]. CDC guideline for prescribing opioids for chronic pain. Available from: https://www.cdc.gov/drugoverdose/prescribing/guideline.html. Accessed November 8, 2017.

32. Alimi Y, Economopoulos KP, Smelser W, Tanner A, Sudarshan M, Hon $\mathrm{H}$ [database on the Internet]. Postoperative opioid prescriptions: how surgeons can alleviate the opioid crisis. Available from: http://bulletin. facs.org/2017/08/postoperative-opioid-prescriptions-how-surgeonscan-alleviate-the-opioid-crisis/\#.W0ZhftVKjcs. Accessed July 11, 2018

33. El-Boghdadly K, Chin KJ. Local anesthetic systemic toxicity: continuing professional development. Can J Anaesth. 2016;63(3):330-349.

34. Rahiri J, Tuhoe J, Svirskis D, Lightfoot NJ, Lirk PB, Hill AG. Systematic review of the systemic concentrations of local anaesthetic after transversus abdominis plane block and rectus sheath block. Br J Anaesth. 2017;118(4):517-526.

35. Hu D, Onel E, Singla N, Kramer WG, Hadzic A. Pharmacokinetic profile of liposome bupivacaine injection following a single administration at the surgical site. Clin Drug Investig. 2013;33(2):109-115.

36. Dagenais S, Scranton R, Joyce AR, Vick CC. A comparison of approaches to identify possible cases of local anesthetic systemic toxicity in the FDA Adverse Event Reporting System (FAERS) database. Expert Opin Drug Saf. 2018;17(6):545-552.

37. Truven Health Analytics. The Cost of Having a Baby in the United States. Ann Arbor, MI; 2013.

38. Bowers J, Cheyne H. Reducing the length of postnatal hospital stay: implications for cost and quality of care. BMC Health Serv Res. 2016;16:16.
Journal of Pain Research

\section{Publish your work in this journal}

The Journal of Pain Research is an international, peer reviewed, open access, online journal that welcomes laboratory and clinical findings in the fields of pain research and the prevention and management of pain. Original research, reviews, symposium reports, hypothesis formation and commentaries are all considered for publication.

\section{Dovepress}

The manuscript management system is completely online and includes a very quick and fair peer-review system, which is all easy to use. Visit http://www.dovepress.com/testimonials.php to read real quotes from published authors. 